\title{
Efeito de Pontas de Pulverização na Deposição e na Dessecação em Plantas de Brachiaria brizantha ${ }^{1}$
}

\author{
Nozzle Effect on Deposition and Desiccation on Brachiaria brizantha Plants
}

COSTA, N.V. ${ }^{2}$, RODRIGUES, A.C.P. ${ }^{3}$, MARTINS, D. ${ }^{4}$, CARDOSO, L.A. ${ }^{3}$ e SILVA. J.I.C. ${ }^{3}$

RESUMO - Objetivou-se com este trabalho avaliar a eficiência de pontas de pulverização com diferentes vazões e tamanhos de gotas na deposição e na dessecação de plantas de Brachiaria brizantha cv. Marandu, além da quantificação das perdas da calda de pulverização para o solo. O delineamento experimental adotado foi o de blocos casualizados, com quatro repetições. Cada unidade experimental constituiu-se de três linhas de $5 \mathrm{~m}$ de comprimento, espaçadas de $1 \mathrm{~m}$. A aplicação dos tratamentos foi realizada 16 meses após a semeadura da braquiária; 40 dias antes da aplicação foi realizada uma roçagem para uniformização da área. Foram avaliadas as pontas de pulverização de jato plano XR $11001 \mathrm{VS}\left(100 \mathrm{~L} \mathrm{ha}^{-1}\right)$ e XR 11002 VS (200 L ha-1), jato cônico TX-4VS (100 L ha-1) e TX-8 VK (200 L ha-1), ponta com indução de ar AI 11002 VS (200 L ha-1) e jato plano duplo TJ60 11002 VS (200 L ha-1). A calda foi aplicada com o herbicida glyphosate na dose de $1.800 \mathrm{~g} \mathrm{ha}^{-1}$, mais um traçador (FD\&C n 1 $2.000 \mathrm{ppm})$. Foram coletados imediatamente após a aplicação da calda 25 perfilhos por repetição, sendo lavadas separadamente as folhas e caules de cada perfilho em $150 \mathrm{ml}$ de água destilada, para posterior quantificação do traçador em espectrofotômetro. Os dados foram ajustados à curva de regressão pelo modelo de Gompertz. Todas as pontas utilizadas foram eficientes na dessecação das plantas de $B$. brizantha, independentemente do volume utilizado, o que evidencia a possibilidade de redução do volume de aplicação e da dosagem do herbicida na dessecação de pastagens, considerando-se a utilização de herbicidas sistêmicos. Ressalta-se que houve diferença na quantidade e na uniformidade de distribuição da calda pulverizada nos alvos avaliados em função da ponta testada e, conseqüentemente, do volume utilizado.

Palavras-chave: controle químico, tecnologia de aplicação, traçador, glyphosate, pastagem.

ABSTRACT - The objective of this work was to evaluate the effect of spray nozzles with different flows and droplet size on the deposition and desiccation of Brachiaria brizantha cv. Marandu plants. A complete randomized block design was used with four replications. Each experimental unit consisted of three $1 \mathrm{~m}$ spaced, $5 \mathrm{~m}$ long lines. The treatments were applied $16 \mathrm{months}$ after seeding, and 40 days before application $B$. brizantha was cut to render the area uniform. The following types of nozzles were evaluated:fat flan nozzle XR $11001 \mathrm{VS}\left(100 \mathrm{~L} \mathrm{ha} \mathrm{h}^{-1}\right)$ and XR 11002

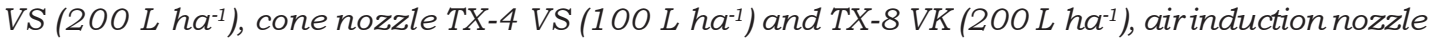
AI 11002 VS (200 L ha-1) and double flat fan nozzle TJ 6011002 VS (200 L ha' $)$. The solution was sprayed with the glyphosate at 1,800 $\mathrm{g} \mathrm{ha}^{-1}$, plus a tracer solution. After application, 25 plants per replication were collected immediately after spraying and the leaves and stem were washed separately in $150 \mathrm{ml}$ of distilled water for posterior tracer quantification in a spectrophotometer. The data obtained were adjusted to a regression curve by the Gompertz model. All the spray nozzles used were efficient in controlling $\boldsymbol{B}$. brizantha plants, regardless of the application

1 Recebido para publicação em 30.8.2007 e na forma revisada em 20.2.2008.

2 Doutor em Agronomia/Agricultura < neumarciove@hotmail.com>; ${ }^{3}$ Doutorando em Agronomia do Dep. de Produção Vegetal da FCA-UNESP, Botucatu-SP, ${ }^{4}$ Prof. Adjunto do Dep. de Produção Vegetal da FCA-UNESP, Fazenda Lageado, Caixa Postal 237, 18603-970, Botucatu-SP 
volume applied, showing that it is possible to reduce the application volume and herbicide dosage in pasture desiccation, considering the use of systemic herbicides. It must be highlighted that there was a difference in the amount and distribution uniformity of the solution sprayed on the targets evaluated, according to the type of spray nozzles tested, and consequently, volume used.

Keywords: chemical control, application technology, tracer, glyphosate, pasture

\section{INTRODUÇÃO}

A eficiência do tratamento fitossanitário não depende somente da quantidade de produto ativo depositado na planta, mas também da uniformidade e da distribuição desse produto sobre a superficie-alvo. Os equipamentos de pulverização têm a função de distribuir o produto no tamanho de gotas adequado sobre o alvo (Foloni, 1995; Rodrigues, 2006).

A dessecação eficiente das plantas utilizadas como cobertura é um dos fatores mais importantes para o sucesso do estabelecimento de culturas graniferas, pois permite que a cultura se desenvolva inicialmente livre de interferências (Almeida, 1991).

O sucesso da dessecação consiste em uma cobertura mínima, uniforme e de elevada qualidade e está diretamente relacionado com o diâmetro das gotas, que também estabelece o seu comportamento quanto à distância de deslocamento (deriva), à penetração na folhagem, à perda por evaporação e, conseqüentemente, à taxa de recuperação (Ferreira et al., 2000), além dos fatores relacionados com a arquitetura e anatomia das plantas (Taylor \& Shaw, 1993). A uniformidade de distribuição está intimamente relacionada à regulagem perfeita do equipamento, à velocidade de trabalho e à escolha das pontas (Cristofoletti, 1998). Dessa forma, estudos de tecnologias de aplicação tornaram-se importantes para aumentar a eficiência da chegada das gotas no alvo (Costa, 1997).

Entre os estudos de metodologias para quantificação de depósitos de calda, destacamse os resultados de Maciel et al. (2001), que trabalharam com depósitos de calda em feijão e Brachiaria plantaginea, no qual observaram que a deposição estimada por área foliar $\left(\mu \mathrm{L} \mathrm{cm}^{2}\right)$, bem como por massa seca de plantas $\left(\mathrm{g} \mathrm{cm}^{-1}\right)$, apresentou resultados semelhantes.
Da mesma forma, Tomazella (2001) observou que qualquer um dos dois parâmetros utilizados para quantificar a deposição apresentavase adequado para a quantificação em plantas de B. plantaginea.

O efeito do glyphosate, que é um herbicida sistêmico e usado em várias concentrações e vários volumes de aplicação no controle de plantas infestantes, tem sido pesquisado em várias culturas. Na maioria dos estudos, a concentração maior de glyphosate com volumes menores tem proporcionado melhor controle de plantas infestantes (Jordan, 1981, 1983; Buhler \& Burnside, 1987; McWhorter \& Hanks, 1993).

A eficiência da pulverização de produtos fitossanitários é maximizada quando são utilizadas pontas de pulverização que propiciem distribuição uniforme e espectro de gotas semelhante e de tamanho adequado (Cunha, 2003). A distribuição da calda de pulverização no alvo de maneira desuniforme e abaixo do volume mínimo exigido pode resultar em controle ineficiente, e a utilização de volumes acima do exigido pode causar perdas financeiras, toxidez nas culturas e contaminação ao ambiente (Cordeiro, 2001). Assim, ainda são restritas as informações sobre as melhores recomendações operacionais em aplicações de dessecantes em pastagens, principalmente no que se refere à qualidade da deposição da calda de pulverização.

Objetivou-se com este trabalho avaliar a eficiência de pontas de pulverização na deposição e dessecação de plantas de $B$. brizantha cv. Marandu com o herbicida glyphosate, além da quantificação das perdas da calda de pulverização para o solo.

\section{MATERIAL E MÉTODOS}

O presente trabalho foi realizado em condição de campo na Fazenda Experimental 
Lageado, da Faculdade de Ciências Agronômicas - FCA/UNESP, campus de Botucatu/SP. As coordenadas geográficas da área são: latitude de $22^{\circ} 07^{\prime} 56^{\prime \prime}$ S e longitude de $74^{\circ} 66^{\prime} 84^{\prime \prime}$ WGr, com altitude média de $762 \mathrm{~m}$.

O delineamento experimental utilizado foi de blocos casualizados, com quatro repetições. Cada unidade experimental constituiu-se de três linhas de $5 \mathrm{~m}$ de comprimento, espaçadas de $1 \mathrm{~m}$. A aplicação dos tratamentos foi realizada 16 meses após o plantio de $B$. brizantha; aos 40 dias antes da aplicação foi realizada uma roçada para uniformização da área. As plantas, na época da aplicação dos tratamentos, apresentavam-se com 40-60 cm de altura.

Foram testados seis tratamentos (Tabela 1) com aplicação de glyphosate na dose de $1.800 \mathrm{~g} \mathrm{ha}^{-1}$ mais um traçador, para avaliar a eficiência das pontas de pulverização na deposição, bem como na dessecação da braquiária.

A avaliação da deposição foi realizada por meio da técnica proposta por Palladini (2000), utilizando-se como traçador o corante alimentício Azul Brilhante (FD\&C no 1 ), adicionado à calda de pulverização na concentração de $2.000 \mathrm{ppm}$.

Caixas plásticas tipo gerbox com dimensões de $11,5 \times 11,5 \times 3,0 \mathrm{~cm}$ foram utilizadas como alvo não-biológico e colocadas em cada parcela experimental para se avaliar a eficiência da deposição proporcionada por cada ponta de pulverização e determinar a quantidade de traçador que atingiu o solo. Foram colocadas quatro caixas na entrelinha e quatro na linha da cultura, distribuídas ao acaso antes da pulverização.

Imediatamente após a aplicação da calda, 25 perfilhos foram coletados por repetição, armazenando-se separadamente as folhas e caules de cada perfilho em sacos plásticos. As amostras foram levadas ao laboratório e lavadas com $150 \mathrm{ml}$ de água destilada. Para quantificar a solução do traçador após lavagem das folhas e caules, foi determinada a densidade óptica (absorbância $=630 \mathrm{~nm}$ ) das soluções, com um espectrofotômetro de UV visivel GBC.

Após a lavagem, as plantas foram colocadas em sacos de papel etiquetados e levadas à estufa de ventilação forçada de ar para secagem. Após 72 horas, em temperatura de $60^{\circ} \mathrm{C}$, as plantas foram retiradas e pesadas, determinando-se a massa seca.

As condições climáticas durante a aplicação variaram em torno de 26,8 a $29,6^{\circ} \mathrm{C}$ de temperatura do ar, 57 a $73 \%$ de umidade relativa e velocidade do vento em rajadas de aproximadamente $1 \mathrm{~m} \mathrm{~s}^{-1}$.

O herbicida foi aplicado com um pulverizador costal pressurizado a $\mathrm{CO}_{2}$ e com reservatório de 10 litros. A barra de aplicação estava equipada com seis pontas, distanciadas de $50 \mathrm{~cm}$ entre si. Durante a aplicação, as parcelas foram protegidas por placas de lona plástica de $2,5 \mathrm{~m}$ de altura, para evitar deriva da pulverização para as parcelas laterais. As pressões utilizadas em cada tratamento estão apresentadas na Tabela 1 .

Tabela 1 - Tratamentos utilizados no estudo da dessecação de plantas de Brachiaria brizantha cv. Marandu com o herbicida glyphosate. Botucatu-SP, 2005

\begin{tabular}{|c|c|c|c|}
\hline Tratamento & $\begin{array}{c}\text { Volume } \\
\left(\mathrm{L} \mathrm{ha}^{-1}\right)\end{array}$ & $\begin{array}{c}\text { Pressão } \\
(\mathrm{kPa})\end{array}$ & Classificação das gotas* \\
\hline XR 11001 VS & 100 & 160 & Fina \\
\hline XR 11002 VS & 200 & 210 & Fina \\
\hline TX-4 VS & 100 & 350 & Muito Fina \\
\hline TX-8 VK & 200 & 450 & Muito Fina \\
\hline AI 11002 VS & 200 & 200 & Extremamente Grossa \\
\hline TJ60 11002 VS & 200 & 190 & Fina \\
\hline
\end{tabular}

* SPRAYING SYSTEMS Co. (2000)

Os efeitos do herbicida na dessecação das plantas de braquiária foram avaliados visualmente, por escala de percentual de notas, na qual 0 (zero) corresponde a nenhuma injúria demonstrada pela planta e 100 (cem) à morte das plantas, segundo a Sociedade Brasileira da Ciência das Plantas Daninhas - SBCPD (1995).

As avaliações de controle das plantas de braquiária foram realizadas aos 7, 14, 21, 28 e 38 dias após a aplicação dos herbicidas. Os parâmetros utilizados para estabelecimento das notas foram: inibição do crescimento, quantidade e uniformidade das injúrias, capacidade de rebrota das plantas, quantidade de plantas mortas e acúmulo de biomassa. Ao final do experimento foi avaliada a matéria seca das plantas, para determinar o acúmulo de biomassa. 
Os dados dos depósitos, em porcentagem, foram ajustados pelo modelo de Gompertz $(\mathrm{F}=$ $\left.\mathrm{e}^{\wedge}\left(\mathrm{a}-\mathrm{e}^{\wedge}\left(-b-c^{*} \mathrm{X}\right)\right)\right)$, para representar a freqüência acumulada $(\mathrm{F})$ da deposição da calda pulverizada, em porcentagem. Adotou-se o valor 4,60517 para o parâmetro "a" do modelo, o qual representa a assintota máxima da curva, em que " $\mathrm{e}$ " $=100$, conforme o modelo modificado por Velini (1995). O deslocamento da curva ao longo do eixo $\mathrm{x}$ é representado pelo módulo do parâmetro "a", e a inclinação ou concavidade da curva em relação à freqüência acumulada, pelo parâmetro "c". Além disso, para melhor visualização, optou-se por apresentar as freqüências não-acumuladas $\left(\mathrm{FN}=\mathrm{c}^{*} \mathrm{e}^{\wedge}(\mathrm{a}-\mathrm{b}-\right.$ $\left.\left.c^{*} X-e^{\wedge}\left(-b-c^{*} X\right)\right)\right)$, que correspondem à derivada primeira do modelo. As freqüências acumuladas e não-acumuladas do modelo de Gompertz permitem a interpretação biológica dos resultados. Para facilitar a visualização das informações, a derivada primeira corresponde à moda da deposição da solução pulverizada nos alvos específicos (Velini, 1995).

Os valores de média, moda e mediana também foram calculados. A precisão do ajuste dos dados do modelo de Gompertz foi avaliada por meio dos coeficientes de determinação $\left(R^{2}\right)$ e pela soma dos quadrados dos resíduos das equações.

Os resultados foram submetidos à análise de variância pelo teste $\mathrm{F}$; os valores em porcentagem foram transformados em arco seno $\sqrt{\mathrm{x} / 100}$, e as médias, comparadas pelo teste LSD a 5\% (Zar, 1984).

Os dados originais dos depósitos da calda de pulverização em $\mu \mathrm{L} \mathrm{g}^{-1}$ de massa seca de folhas, caule e de perfilho de braquiária foram analisados através de regressões, sendo os valores ajustados pelo modelo de Gompertz.

\section{RESULTADOS E DISCUSSÃO}

Na Tabela 2 são apresentadas as porcentagens de depósitos da calda de pulverização que alcançaram o solo durante a dessecação de plantas de $B$. brizantha. Independentemente da ponta e do volume utilizado, os depósitos de calda no solo foram semelhantes e variaram entre 14,7 e 20,6\% do volume total aplicado. Um aspecto importante desses resultados refere-se a uma possivel aplicação de herbicidas
Tabela 2 - Porcentagem de depósitos da calda de pulverização do herbicida glyphosate que alcançou o solo durante a dessecação de plantas de Brachiaria brizantha cv. Marandu. Botucatu-SP, 2005

\begin{tabular}{|c|c|c|}
\hline Tratamento & Volume $\left(\mathrm{L} \mathrm{ha}^{-1}\right)$ & Calda (\%) \\
\hline XR 11001 VS & 100 & 14,7 \\
\hline XR 11002 VS & 200 & 17,7 \\
\hline TX-4 VS & 100 & 16,0 \\
\hline TX-8 VK & 200 & 15,2 \\
\hline AI 11002 VS & 200 & 20,6 \\
\hline TJ60 11002 VS & 200 & 17,6 \\
\hline F Tratamento & - & $0,320^{\text {ns }}$ \\
\hline F $_{\text {Bloco }}$ & - & $1,020^{\text {ns }}$ \\
\hline CV (\%) & - & 21,16 \\
\hline d.m.s. & - & 0,134 \\
\hline
\end{tabular}

Dados de porcentagem foram transformados em arco seno $\sqrt{\mathrm{x} / 100}$

Médias seguidas de mesma letra na coluna não diferem estatisticamente entre si pelo teste LSD $(p>0,05)$.

${ }^{\text {ns }}$ Não-significativo.

para o controle de plantas daninhas em pastagens em pós-emergência, que possua efeito residual em pré-emergência, pois poderão promover também o controle do banco de semente; dessa forma, não seria considerado perda os depósitos que alcançaram o solo. No entanto, essas aplicações podem apresentar maior risco de contaminação do solo, já que o alvo da pulverização seria a planta de braquiária. Esses resultados também podem ser extrapolados para aplicações de inseticidas no controle da cigarrinha da pastagem, conforme Maciel et al. (2007).

Outro aspecto a ser comentado refere-se à maior deposição no solo proporcionada pela ponta AI 11002 VS, independentemente de ser estatisticamente semelhante aos demais tratamentos, pois este apresentou depósitos superiores de até $28,6 \%$, dependendo da ponta comparada. Estudos com pontas de indução de ar devem ser implementados para consolidação ou não desses maiores depósitos que foram observados.

Os resultados das análises de regressão, as estimativas dos parâmetros do modelo de Gompertz, a média, a moda e a mediana estão apresentados na Tabela 3 (folha), Tabela 4 (caule) e Tabela 5 (perfilho - planta inteira); na Figura 1 encontram-se as freqüências acumuladas (FA\%) e as freqüências não- 
Efeito de pontas de pulverização na deposição e na...

Tabela 3 - Resultados das análises de regressão das freqüências acumuladas dos depósitos da calda do herbicida glyphosate em folhas de Brachiaria brizantha cv. Marandu, utilizando o modelo de Gompertz, bem como as médias, modas e medianas $\left(\mu \mathrm{L} \mathrm{g}^{-1}\right)$, das diferentes pontas de pulverização. Botucatu-SP, 2005

\begin{tabular}{|c|c|c|c|c|c|c|c|}
\hline \multirow{2}{*}{\multicolumn{2}{|c|}{ Modelo }} & \multicolumn{6}{|c|}{ Freqüência acumulada $(\%)=\mathrm{e}^{\wedge}\left[\mathrm{A}-\mathrm{e}^{\wedge}\left(-\mathrm{B}-\mathrm{C}^{*} \mathrm{X}\right)\right]$} \\
\hline & & \multirow{2}{*}{$\begin{array}{c}\begin{array}{c}\text { XR 11001 } \\
\left(100 \mathrm{~L} \mathrm{ha}^{-1}\right)\end{array} \\
4,60517\end{array}$} & \multirow{2}{*}{$\begin{array}{c}\begin{array}{c}\text { XR } 11002 \\
\left(200 \mathrm{~L} \mathrm{ha}^{-1}\right)\end{array} \\
4,60517\end{array}$} & \multirow{2}{*}{$\begin{array}{c}\text { TX-4 } \\
\left(100 \mathrm{~L} \mathrm{ha}^{-1}\right)\end{array}$} & \multirow{2}{*}{$\begin{array}{c}\begin{array}{c}\text { TX-8 } \\
\left(200 \mathrm{~L} \mathrm{ha}^{-1}\right)\end{array} \\
4,60517\end{array}$} & \multirow{2}{*}{$\begin{array}{c}\begin{array}{c}\text { AI } 11002 \\
\left(200 \mathrm{Lha}^{-1}\right)\end{array} \\
4,60517\end{array}$} & \multirow{2}{*}{$\begin{array}{c}\begin{array}{c}\text { TJ60 } 11002 \\
\left(200 \mathrm{Lha}^{-1}\right)\end{array} \\
4,60517\end{array}$} \\
\hline \multirow{3}{*}{$\begin{array}{l}\text { Estimativa } \\
\text { dos } \\
\text { parâmetros }\end{array}$} & A & & & & & & \\
\hline & $\mathrm{B}$ & $-1,53856$ & $-2,67292$ & $-1,32045$ & $-2,37587$ & $-2,17347$ & $-2,11854$ \\
\hline & $\mathrm{C}$ & 0,02319 & 0,02596 & 0,02401 & 0,02533 & 0,01908 & 0,02560 \\
\hline \multicolumn{2}{|l|}{$S Q_{\text {Regressão }}$} & 337558,0087 & 338174,2509 & 337760,9815 & 338144,7274 & 338204,1377 & 337609,0607 \\
\hline \multicolumn{2}{|l|}{$\mathrm{SQ}_{\text {Resíduo }}$} & 791,9913 & 175,7491 & 589,01851 & 205,2726 & 145,8623 & 740,9393 \\
\hline \multicolumn{2}{|l|}{$\mathrm{SQ}_{\text {Total }}$} & 83325,0000 & 83325,0000 & 83325,0000 & 83325,0000 & 83325,0000 & 83325,0000 \\
\hline \multicolumn{2}{|l|}{$F_{\text {Regressão }}$} & $20884,5102 *$ & $94285,0992 *$ & $28098,0919^{*}$ & $80717,4398^{*}$ & $113614,0856^{*}$ & $22326,8401 *$ \\
\hline \multicolumn{2}{|l|}{$\mathrm{R}^{2}$} & 0,9905 & 0,9979 & 0,9929 & 0,9975 & 0,9982 & 0,9911 \\
\hline \multicolumn{2}{|l|}{ Média } & 99,68 & 125,17 & 86,03 & 119,65 & 147,74 & 102,00 \\
\hline \multicolumn{2}{|l|}{ Moda } & 66,35 & 102,98 & 55,00 & 93,81 & 113,92 & 82,75 \\
\hline \multicolumn{2}{|l|}{ Mediana } & 82,16 & 117,10 & 70,27 & 108,28 & 133,13 & 97,06 \\
\hline \multicolumn{2}{|l|}{$\mathrm{CV}(\%)$} & 2,85 & 1,07 & 2,85 & 1,21 & 0,83 & 2,70 \\
\hline
\end{tabular}

$\mathrm{X}=$ porcentagem de depósito do traçador em relação ao total aplicado; A, B e C são estimativas dos parâmetros do modelo para o traçador. * Significativo a $1 \%$ de probabilidade.

Tabela 4 - Resultados das análises de regressão das freqüências acumuladas dos depósitos da calda do herbicida glyphosate em caules de Brachiaria brizantha cv. Marandu, utilizando o modelo de Gompertz, bem como as médias, modas e medianas $\left(\mu \mathrm{L} \mathrm{g}{ }^{-1}\right)$, das diferentes pontas de pulverização. Botucatu-SP, 2005

\begin{tabular}{|c|c|c|c|c|c|c|c|}
\hline \multirow{2}{*}{\multicolumn{2}{|c|}{ Modelo }} & \multicolumn{6}{|c|}{ Freqüência acumulada $(\%)=\mathrm{e}^{\wedge}\left[\mathrm{A}-\mathrm{e}^{\wedge}\left(-\mathrm{B}-\mathrm{C}^{*} \mathrm{X}\right)\right]$} \\
\hline & & \multirow{2}{*}{$\begin{array}{r}\begin{array}{r}\text { XR } 11001 \\
\left(100 \mathrm{~L} \mathrm{ha}^{-1}\right)\end{array} \\
4,60517\end{array}$} & \multirow{2}{*}{$\begin{array}{r}\begin{array}{l}\text { XR } 11002 \\
\left(200 \mathrm{~L} \mathrm{ha}^{-1}\right)\end{array} \\
4,60517\end{array}$} & \multirow{2}{*}{$\begin{array}{c}\begin{array}{c}\text { TX-4 } \\
\left(100 \mathrm{Lha}^{-1}\right)\end{array} \\
4,60517\end{array}$} & \multirow{2}{*}{$\begin{array}{c}\begin{array}{c}\text { TX-8 } \\
\left(200 \mathrm{Lha}^{-1}\right)\end{array} \\
4,60517\end{array}$} & \multirow{2}{*}{$\begin{array}{r}\begin{array}{c}\text { AI } 11002 \\
\left(200 \mathrm{Lha}^{-1}\right)\end{array} \\
4,60517\end{array}$} & \multirow{2}{*}{$\begin{array}{r}\begin{array}{r}\text { TJ60 } 11002 \\
\left(200 \text { Lha }^{-1}\right)\end{array} \\
4,60517\end{array}$} \\
\hline Estimativa & A & & & & & & \\
\hline & $\mathrm{B}$ & $-1,62129$ & $-1,74169$ & $-1,13102$ & $-1,57164$ & $-1,60973$ & $-1,53829$ \\
\hline parämetros & $\mathrm{C}$ & 0,11745 & 0,10428 & 0,08728 & 0,12081 & 0,16724 & 0,11474 \\
\hline \multicolumn{2}{|l|}{$S Q_{\text {Regressão }}$} & 338093,4465 & 337353,3227 & 336246,1198 & 337386,7167 & 337918,6621 & 336909,3179 \\
\hline \multicolumn{2}{|l|}{ SQ Resíduo } & 256,5535 & 996,6774 & 2103,88018 & 963,2833 & 431,3379 & 1440,6822 \\
\hline \multicolumn{2}{|l|}{$\mathrm{SQ}_{\text {Total }}$} & 83325,0000 & 83325,0000 & 83325,0000 & 83325,0000 & 83325,0000 & 83325,0000 \\
\hline \multicolumn{2}{|l|}{$\mathrm{F}_{\text {Regressão }}$} & $64573,6541 *$ & $16585,4155^{*}$ & $7831,2711 *$ & $17162,0867 *$ & $38387,5465^{*}$ & $11458,8458^{*}$ \\
\hline \multicolumn{2}{|l|}{$\mathrm{R}^{2}$} & 0,9969 & 0,9880 & 0,9748 & 0,9884 & 0,9948 & 0,9827 \\
\hline \multicolumn{2}{|l|}{ Média } & 18,93 & 25,80 & 23,41 & 19,62 & 16,42 & 22,24 \\
\hline \multicolumn{2}{|l|}{ Moda } & 13,80 & 16,70 & 12,96 & 13,01 & 9,63 & 13,41 \\
\hline \multicolumn{2}{|l|}{ Mediana } & 16,92 & 20,22 & 17,16 & 16,04 & 11,82 & 16,60 \\
\hline \multicolumn{2}{|l|}{$\mathrm{CV}(\%)$} & 8,55 & 12,36 & 19,79 & 15,98 & 12,78 & 17,24 \\
\hline
\end{tabular}

$\mathrm{X}=$ porcentagem de depósito do traçador em relação ao total aplicado; A, B e C são estimativas dos parâmetros do modelo para o traçador. * Significativo a $1 \%$ de probabilidade. 
Tabela 5 - Resultados das análises de regressão das freqüências acumuladas dos depósitos da calda do herbicida glyphosate em perfilho (planta inteira) de Brachiaria brizantha cv. Marandu, utilizando o modelo de Gompertz, bem como as médias, modas e medianas $\left(\mu \mathrm{L} \mathrm{g}^{-1}\right)$, das diferentes pontas de pulverização. Botucatu-SP, 2005

\begin{tabular}{|c|c|c|c|c|c|c|c|}
\hline \multirow{2}{*}{ Modelo } & & \multicolumn{6}{|c|}{ Freqüência acumulada $(\%)=\mathrm{e}^{\wedge}\left[\mathrm{A}-\mathrm{e}^{\wedge}\left(-\mathrm{B}-\mathrm{C}^{*} \mathrm{X}\right)\right]$} \\
\hline & & $\begin{array}{l}\text { XR } 11001 \\
\left(100 \mathrm{~L} \mathrm{ha}^{-1}\right)\end{array}$ & $\begin{array}{l}\text { XR } 11002 \\
\left(200 \mathrm{~L} \mathrm{ha}^{-1}\right)\end{array}$ & $\begin{array}{c}\text { TX-4 } \\
\left(100 \mathrm{~L} \mathrm{ha}^{-1}\right)\end{array}$ & $\begin{array}{c}\text { TX-8 } \\
\left(200 \mathrm{~L} \mathrm{ha}^{-1}\right)\end{array}$ & $\begin{array}{c}\text { AI } 11002 \\
\left(200 \mathrm{~L} \mathrm{ha}^{-1}\right)\end{array}$ & $\begin{array}{l}\text { TJ60 } 11002 \\
\left(200 \mathrm{~L} \mathrm{ha}^{-1}\right)\end{array}$ \\
\hline \multirow{3}{*}{$\begin{array}{l}\text { Estimativa } \\
\text { dos } \\
\text { parâmetros }\end{array}$} & $\mathrm{A}$ & 4,60517 & 4,60517 & 4,60517 & 4,60517 & 4,60517 & 4,60517 \\
\hline & $\mathrm{B}$ & $-1,86297$ & $-2,69177$ & $-1,50382$ & $-2,58486$ & $-2,16024$ & $-2,49747$ \\
\hline & $\mathrm{C}$ & 0,04098 & 0,03851 & 0,03618 & 0,04138 & 0,03005 & 0,04446 \\
\hline \multicolumn{2}{|l|}{$S Q_{\text {Regressão }}$} & 337799,4432 & 337944,2163 & 337892,8497 & 338000,2975 & 338200,4238 & 337985,1143 \\
\hline \multicolumn{2}{|l|}{$\mathrm{SQ}_{\text {Resíduo }}$} & 550,5568 & 405,7837 & 457,15033 & 349,7025 & 149,5762 & 364,8857 \\
\hline \multicolumn{2}{|l|}{$\mathrm{SQ}_{\text {Total }}$} & 83325,0000 & 83325,0000 & 83325,0000 & 83325,0000 & 83325,0000 & 83325,0000 \\
\hline \multicolumn{2}{|l|}{$\mathrm{F}_{\text {Regressão }}$} & $30064,4048 *$ & $40808,1118^{*}$ & $36217,2922 *$ & $47360,3358 *$ & $110791,6660 *$ & $45387,5995^{*}$ \\
\hline \multicolumn{2}{|l|}{$\mathrm{R}^{2}$} & 0,9934 & 0,9951 & 0,9945 & 0,9958 & 0,9982 & 0,9956 \\
\hline \multicolumn{2}{|l|}{ Média } & 60,68 & 84,13 & 61,68 & 78,44 & 93,41 & 68,90 \\
\hline \multicolumn{2}{|l|}{ Moda } & 45,46 & 69,90 & 41,57 & 62,47 & 71,89 & 56,17 \\
\hline \multicolumn{2}{|l|}{ Mediana } & 54,41 & 79,41 & 51,70 & 71,33 & 84,09 & 64,42 \\
\hline \multicolumn{2}{|l|}{$\mathrm{CV}(\%)$} & 3,91 & 2,42 & 3,50 & 2,41 & 1,32 & 2,80 \\
\hline
\end{tabular}

$\mathrm{X}=$ porcentagem de depósito do traçador em relação ao total aplicado; A, B e C são estimativas dos parâmetros do modelo para o traçador ** Significativo a $1 \%$ de probabilidade.

acumuladas (FNA\%) das pontas utilizadas nas folhas, caules e perfilhos (planta inteira) de $B$. brizantha.

Nota-se na Figura 1 (A - B) e na Tabela 3 que a ponta $\mathrm{AI} 11002 \mathrm{VS}$ foi a que proporcionou a maior deposição da calda de pulverização, seguida pela ponta XR 11002 VS, com valores da moda de 113,92 e $102,98 \mu \mathrm{L} \mathrm{g}^{-1}$ de massa seca de folha, respectivamente, e ambas com volume de $200 \mathrm{~L} \mathrm{ha}^{-1}$. Esse maior depósito obtido pela ponta AI 11002 VS pode ser justificado pelo fato de ela produzir gotas extremamente grossas em relação à ponta XR 11002 VS $(200 \mathrm{kPa})$, que produz gotas finas. Assim, a maior deposição da calda sobre as folhas pode significar a possibilidade de melhor eficiência no controle, uma vez que ocorre maior concentração de herbicida por unidade de planta. Nas pontas TJ60 11002 VS e TX-8 VK, ambas no volume de $200 \mathrm{~L} \mathrm{ha}^{-1}$, observam-se valores de moda de 27,4 e $17,7 \%$, inferiores em relação aos da ponta AI 11002 VS. A ponta TX-4 VS, que produz gotas muito finas, foi a que proporcionou a menor deposição, seguida pela ponta XR $11001 \mathrm{VS}$, com valores da moda inferiores em 51,7 e 41,8\%, respectivamente, em relação à ponta AI 11002 VS.
É importante ressaltar que a utilização das pontas TX-4 VS e XR 11001 VS no manejo de dessecação de plantas de braquiárias pode apresentar algumas limitações com relação ao aspecto prático da aplicação e de contaminação do ambiente, principalmente quando as condições climáticas no momento da aplicação do dessecante apresentarem ventos acentuados e temperatura elevada, pois esses fatores podem aumentar significativamente a perda das gotas por deriva, por serem muito finas.

Utilizando o parâmetro "C" do modelo de Gompertz (Tabela 3), em que os maiores valores indicam menores inclinações das curvas e maior uniformidade de deposição da calda de pulverização, verifica-se que todas as pontas apresentaram uniformidades semelhantes, exceto a ponta AI 11002 VS, que resultou em menor valor para o parâmetro "C" (maior inclinação da curva). Entretanto, esta ponta foi a que proporcionou a maior deposição de calda de pulverização nas folhas, demonstrando, portanto, que nem sempre a ponta que apresenta maior deposição de calda é a que proporciona a melhor uniformidade de distribuição das gotas. As pontas que se destacaram com as melhores uniformidades de deposição nas folhas 

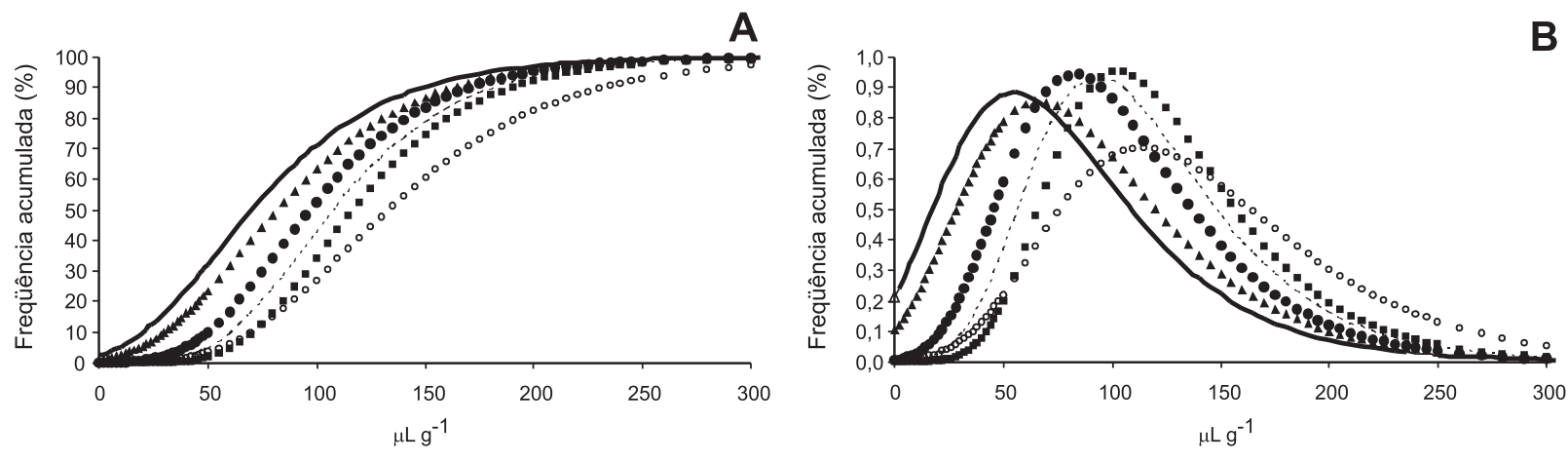

$\Delta \quad X R 11001(100 L) \quad-\quad X R 11002(200 L)-T X-4(100 L)$

- XR $11001(100 \mathrm{~L})$

- XR $11002(200 \mathrm{~L})$ - Al $11002(200 \mathrm{~L})$

- TJ60 $11002(200 \mathrm{~L})$
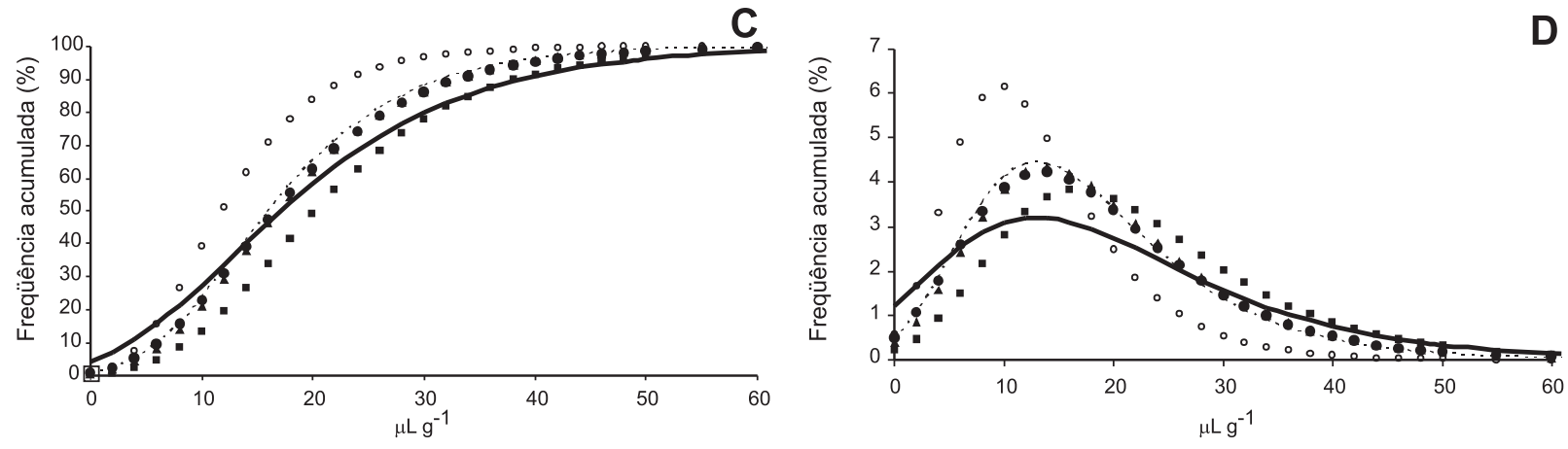

^ XR $11001(100 \mathrm{~L}) \quad$ - XR $11002(200 \mathrm{~L}) \quad \mathrm{TX}-4(100 \mathrm{~L})$

- XR $11001(100 \mathrm{~L})$

- $\quad X R 11002(200 \mathrm{~L}) \quad$ TX-4 $(100 \mathrm{~L})$ ...... TX-8 $(200 \mathrm{~L}) \quad$ Al $11002(200 \mathrm{~L})$ - TJ60 $11002(200 \mathrm{~L}) \quad \ldots . . . . \mathrm{TX}-8(200 \mathrm{~L})$
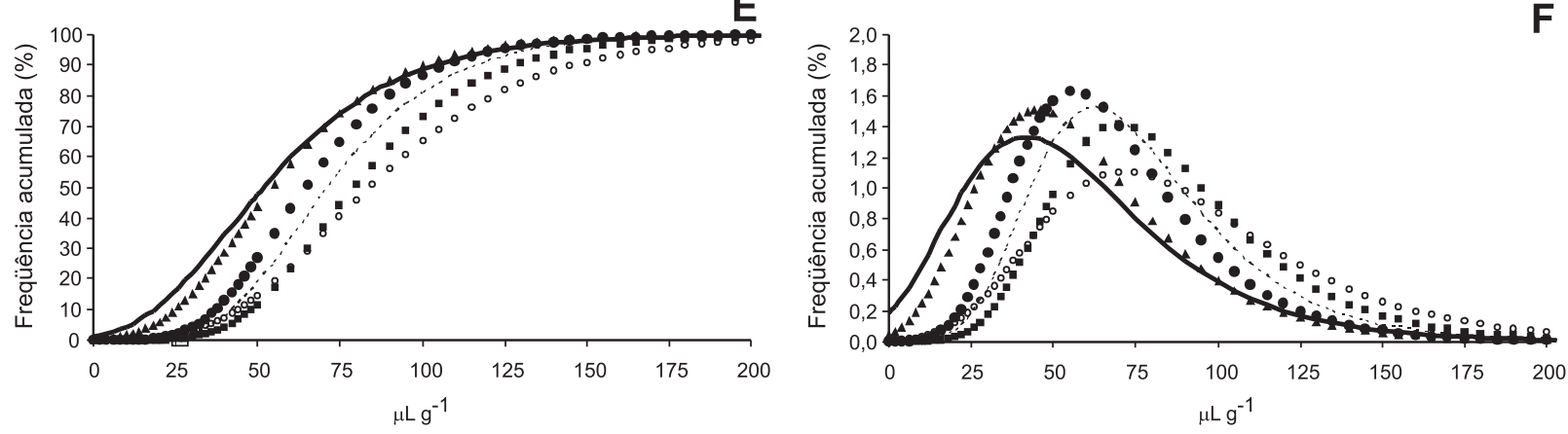

- XR $11001(100 \mathrm{~L})$

- XR 11002 (200 L)

TX-4 (100 L)

- XR $11001(100 \mathrm{~L})$

- $\quad$ XR $11002(200 \mathrm{~L})$ - $\mathrm{AI} 11002(200 \mathrm{~L})$

TX-4 $(100 \mathrm{~L})$
- TJ60 $11002(200 \mathrm{~L})$

Figura 1 - Freqüências acumuladas (FA\%): (A, C e E), e não-acumuladas (FNA\%): (B, D e F), em função da deposição da calda de pulverização do herbicida glyphosate em $\mu \mathrm{L} \mathrm{g}^{-1}$ de massa seca de folhas (A e B), caule (C e D) e perfilho (E e F) de Brachiaria brizantha cv. Marandu. Botucatu-SP 2005.

de braquiária foram XR11002 VS, TJ60 11002 VS e TX-8 VK, e todas com o volume de $200 \mathrm{~L} \mathrm{ha}^{-1}$ (Figura 1-A, B). A uniformidade da deposição da calda de pulverização destaca-se como fator importante no desempenho dos produtos fitossanitários, sobretudo quando se consideram os produtos de ação de contato, que exigem maior área de cobertura do alvo. Dessa forma, a ponta AI 11002 VS não seria a mais indicada para aplicação desses produtos, apesar de ter proporcionando maior deposição em relação às demais.

Para os valores de deposição verificados nos caules das plantas de braquiária, a ponta XR 11002 VS, com o volume de $200 \mathrm{~L} \mathrm{ha}^{-1}$, proporcionou o maior valor da moda, que corresponde à maior deposição de gotas. As aplicações 
com as pontas XR $11001 \mathrm{VS}\left(100 \mathrm{~L}^{\mathrm{ha}}{ }^{1}\right)$, TJ60 11002 VS (200 L ha-1), TX-8 VK (200 L ha' $\left.{ }^{-1}\right)$ e TX-4 VS (100 L ha-1) proporcionaram deposições semelhantes e na ordem de 17,4, 19,7, 22,1 e $22,4 \%$ do volume de aplicação, respectivamente, que foram inferiores às da ponta XR 11002 VS. A ponta AI 11002 VS (200 L ha-1) foi a que obteve a menor deposição de gotas, porém foi a que proporcionou maior uniformidade de distribuição delas. Isso pode ser explicado pelo fato de o tamanho das gotas ser grande e, que facilita a interceptação de partes do caule menos expostas e/ou por escorrimento das gotas depositadas na folha para o caule. A ponta TX-4 VS foi a que proporcionou a menor eficiência na distribuição em relação às demais pontas (Figura 1C, D e Tabela 4).

O caule de braquiária é envolto por uma estrutura denominada de bainha, que possui características anatômicas semelhantes às da folha. Desse modo, o caule pode ser considerado uma região importante para absorção de produtos pulverizados em pós-emergência. Contudo, existem poucas informações relacionadas com a absorção de produtos fitossanitários por essa região em espécies de gramineas.

Na Figura 1 (E-F) e Tabela 5 são apresentados os resultados obtidos para os perfilhos de braquiária (planta inteira). Observa-se pelos valores de moda que a ponta AI 11002 VS proporcionou o maior depósito de calda de pulverização, seguida pela ponta XR 11002 VS, ambas com o volume de $200 \mathrm{~L} \mathrm{ha}^{-1}$. Analisando as pontas TX-4 VS e XR 11001 VS, com o volume de $100 \mathrm{~L} \mathrm{ha}^{-1}$, nota-se que foram as que proporcionaram os menores depósitos de calda, com valores de 42,2 e $36,8 \%$ inferiores, respectivamente, em relação à ponta AI 11002 VS Comparando a uniformidade de distribuição, verifica-se que a ponta TJ60 11002 VS no volume de $200 \mathrm{~L} \mathrm{ha}^{-1}$ foi a que se destacou das demais, com a melhor uniformidade de distribuição. Por outro lado, a ponta AI 11002 VS foi a mais desuniforme na deposição da calda.

Constata-se que as pontas que apresentaram as menores deposições nas folhas, bem como nos perfilhos de braquiária (planta inteira), foram aquelas cujo volume de aplicação testado foi de $100 \mathrm{~L} \mathrm{ha}^{-1}$. Da mesma forma, pontas que produzem gotas extremamente grossas, como é o caso da ponta AI 11002 VS, podem proporcionar maior deposição da calda de pulverização nas folhas e perfilhos de braquiária. Isso se deve ao fato de as gotas grossas serem menos influenciadas por fatores climáticos; assim, pode-se ter uma redução da deriva. Entretanto, essas pontas podem apresentar distribuição desuniforme das gotas no alvo em relação a uma ponta que produz gotas finas, a exemplo daXR 11002 VS e TJ60 11002 VS. Na prática, Souza et al. (2007) concluíram que irregularidades nos depósitos podem levar à necessidade de grande aumento na dose aplicada para que elevados niveis de eficiência de herbicidas sejam alcançados em condições de campo, principalmente quando são considerados herbicidas de contato.

Na Tabela 6 estão apresentados os resultados da eficiência das pontas de pulverização na dessecação das plantas de $B$. brizantha quanto aos valores da massa seca e porcentagem de redução da massa seca. A partir dos 14 DAA, observa-se que todos os tratamentos proporcionaram boa eficiência na dessecação, com valores superiores a $85 \%$ de controle das plantas, exceto a ponta TX-4 VS no volume de $100 \mathrm{~L} \mathrm{ha}^{-1}$, que foi de $75 \%$. Após os $21 \mathrm{DAA}$, todos os tratamentos proporcionaram excelentes controles e acima de $95 \%$, com exceção da ponta TJ60 11002 VS, com 85\% de controle. Ao final das avaliações, aos 38 DAA todas as pontas utilizadas foram eficientes no controle das plantas de braquiária, destacando-se a XR $11002 \mathrm{VS}$ com o volume de $200 \mathrm{~L} \mathrm{ha}^{-1}$, com $99,5 \%$ de controle, sendo a ponta que apresentou maior uniformidade de pulverização nas folhas.

A alta eficiência das pontas de pulverização avaliadas pode ser explicada pela utilização de uma dose alta do glyphosate e de sua ação sistêmica na planta. Assim, doses menores em relação à utilizada apresentariam possivelmente maior efeito da redução do volume de aplicação e entre as pontas de pulverização com relação à eficiência da dessecação das plantas de braquiária.

Com relação aos dados de massa seca de plantas de braquiária, as pontas utilizadas proporcionaram reduções superiores a 50\%; a menor redução foi obtida pela ponta XR 11001 VS, com volume de calda de $100 \mathrm{~L} \mathrm{ha}^{-1}$, e as maiores, pelas pontas XR 11002 VS e TX-8 VK, ambas com volume de calda de $200 \mathrm{~L} \mathrm{ha}^{-1}$. 
Tabela 6 - Eficiência de pontas de pulverização na dessecação de plantas de Brachiaria brizantha cv. Marandu com o herbicida glyphosate. Botucatu-SP, 2005

\begin{tabular}{|c|c|c|c|c|c|c|c|}
\hline Tratamento & $\begin{array}{l}\text { Volume } \\
\left(\mathrm{L} \mathrm{ha}^{-1}\right)\end{array}$ & 7 DAA & 14 DAA & $21 \mathrm{DAA}$ & $28 \mathrm{DAA}$ & $38 \mathrm{DAA}$ & $\begin{array}{c}\text { Massa seca } \\
\left(\mathrm{kg} \mathrm{ha}^{-1}\right)\end{array}$ \\
\hline Testemunha & & - & - & - & - & - & $8637,5 \mathrm{a}$ \\
\hline XR $11001 \mathrm{VS}$ & 100 & 20,5 & 91,3 & 98,8 & 98,8 & $99,0 \mathrm{~b}$ & $4076,5 \mathrm{~b}$ \\
\hline XR 11002 VS & 200 & 26,3 & 87,5 & 98,8 & 98,8 & $99,5 \mathrm{a}$ & $2217,3 \mathrm{c}$ \\
\hline TX-4VS & 100 & 25,5 & 75,0 & 95,8 & 96,3 & $97,8 \mathrm{~b}$ & $2289,5 \mathrm{c}$ \\
\hline TX-8 VK & 200 & 20,5 & 85,0 & 97,5 & 98,3 & $99,0 \mathrm{~b}$ & $2224,0 \mathrm{c}$ \\
\hline AI $11002 \mathrm{VS}$ & 200 & 27,0 & 90,0 & 99,0 & 99,0 & $98,8 \mathrm{~b}$ & $3582,0 \mathrm{bc}$ \\
\hline TJ60 $11002 \mathrm{VS}$ & 200 & 35,0 & 85,0 & 85,0 & 98,0 & $98,8 \mathrm{~b}$ & $2944,5 \mathrm{bc}$ \\
\hline $\mathrm{F}_{\text {Tratamento }}$ & & $0,748^{\mathrm{ns}}$ & $2,379^{\mathrm{ns}}$ & $2,231^{\mathrm{ns}}$ & $1,314^{\mathrm{ns}}$ & $3,243 *$ & $14,090 * *$ \\
\hline $\mathrm{F}_{\text {Bloco }}$ & & $0,316^{\mathrm{ns}}$ & $2,571^{\mathrm{ns}}$ & $2,579^{\mathrm{ns}}$ & $1,995^{\mathrm{ns}}$ & $1,534^{\mathrm{ns}}$ & $1,503^{\mathrm{ns}}$ \\
\hline $\mathrm{CV}(\%)$ & & 28,35 & 8,17 & 3,17 & 3,12 & 2,20 & 33,10 \\
\hline d.m.s. & & 12,779 & 8,429 & 3,932 & 3,887 & 2,793 & 1812,897 \\
\hline
\end{tabular}

Dados de porcentagem foram transformados em arco seno $\sqrt{x / 100}$.

Médias seguidas de mesma letra na coluna não diferem estatisticamente entre si pelo teste " $\mathrm{t}$ " $(\mathrm{p}>0,05)$.

* Significativo a $1 \%$

ns Não-significativo.

Na Tabela 7 estão apresentados os valores dos depósitos da calda de pulverização, expressos em $\mu \mathrm{L} \mathrm{g}^{-1}$ de massa seca, nas populações de plantas (folhas, caules e perfilhos - planta inteira) em que ocorreram menos depósitos.

A população de plantas em que menos ocorreram depósitos da calda de pulverização pode ser responsável pelo insucesso da aplicação de produtos fitossanitários (Negrisoli et al., 2002). Assim, a ponta e o volume de aplicação que proporcionarem os maiores depósitos nas populações de plantas que apresentam maior dificuldade em interceptar as gotas pulverizadas serão a combinação mais eficiente no processo de aplicação de produtos fitossanitários (Rodrigues, 2006).

A ponta XR $11002 \mathrm{VS}$, em aplicação com volume de $200 \mathrm{~L} \mathrm{ha}^{-1}$, proporcionou as maiores deposições nos 1, 5 e 10\% da população em que menos ocorreram depósitos, tanto nas folhas como no caule e perfilho de $B$. brizantha. A ponta TX-4 VS em aplicação com volume de $100 \mathrm{~L} \mathrm{ha}^{-1}$ proporcionou falhas na deposição em pelo menos $1 \%$ das folhas, caules e perfilhos, apresentando também valores inferiores em relação às demais pontas, considerando-se os
5 e $10 \%$ da população em que menos ocorreram depósitos da calda de pulverização. Esse efeito pode resultar em maior probabilidade de ocorrência de rebrote devido às falhas de deposição.

Apesar de todas as pontas avaliadas apresentarem eficiência na dessecação das plantas de braquiária, a redução do volume de aplicação e a utilização de pontas que produzem gotas muito finas, como o modelo TX, podem apresentar falhas na dessecação, pelo efeito da deriva.

Grego (2002), trabalhando em plantio direto, observou que a dessecação em época inadequada pode levar a menor eficiência e rendimento da semeadora, principalmente pela dificuldade de corte da palhada, que pode causar desuniformidade no estande da cultura. No caso das braquiárias, a realização da semeadura de culturas logo após a aplicação do herbicida e enquanto estiver ocorrendo a ação do produto nas plantas daninhas pode levar à maior ocorrência de rebrotes destas, além de possiveis efeitos alelopáticos, e, conseqüentemente, interferir negativamente no crescimento inicial das culturas (Timossi et al., 
Tabela 7 - Deposição da calda de pulverização do herbicida glyphosate em $\mu 1$ de calda $\mathrm{g}^{-1}$ de massa seca, nas populações de folhas, caule e no perfilho de Brachiaria brizantha cv. Marandu em que menos ocorreram depósitos. Botucatu-SP, 2005

\begin{tabular}{|c|c|c|c|c|c|c|}
\hline \multirow{2}{*}{$\begin{array}{c}\text { População } \\
(\%)\end{array}$} & $\begin{array}{l}\text { XR } 11001 \text { VS } \\
\left(100 \mathrm{~L} \mathrm{ha}^{-1}\right)\end{array}$ & $\begin{array}{l}\text { XR } 11002 \text { VS } \\
\left(200 \mathrm{~L} \mathrm{ha}^{-1}\right)\end{array}$ & $\begin{array}{c}\text { TX-4 VS } \\
\left(100 \mathrm{~L} \mathrm{ha}^{-1}\right)\end{array}$ & $\begin{array}{c}\text { TX-8 VK } \\
\left(200 \mathrm{~L} \mathrm{ha}^{-1}\right)\end{array}$ & $\begin{array}{l}\text { AI } 11002 \mathrm{VS} \\
\left(200 \mathrm{~L} \mathrm{ha}^{-1}\right)\end{array}$ & $\begin{array}{l}\text { TJ60 } 11002 \mathrm{VS} \\
\left(200 \mathrm{~L} \mathrm{ha}^{-1}\right)\end{array}$ \\
\hline & \multicolumn{6}{|c|}{ Folha } \\
\hline 1 & 0,49 & 44,14 & 0,0 & 33,51 & 33,88 & 23,10 \\
\hline 5 & 19,03 & 60,71 & 9,30 & 50,49 & 56,41 & 39,89 \\
\hline \multirow[t]{2}{*}{10} & 30,38 & 70,85 & 20,26 & 60,88 & 70,21 & 50,17 \\
\hline & \multicolumn{6}{|c|}{ Caule } \\
\hline 1 & 0,80 & 2,06 & 0,0 & 0,37 & 0,49 & 0,10 \\
\hline 5 & 4,46 & 6,18 & 0,39 & 3,93 & 3,06 & 3,84 \\
\hline \multirow[t]{2}{*}{10} & 6,70 & 8,70 & 3,40 & 6,11 & 4,64 & 6,14 \\
\hline & \multicolumn{6}{|c|}{ Perfilho (planta inteira) } \\
\hline 1 & 8,19 & 30,24 & 0,0 & 25,56 & 21,07 & 21,82 \\
\hline 5 & 18,69 & 41,41 & 11,24 & 35,95 & 35,38 & 31,49 \\
\hline 10 & 25,11 & 48,24 & 18,51 & 42,31 & 44,13 & 37,41 \\
\hline
\end{tabular}

2004). Dessa forma, torna-se fundamental a utilização de pontas de pulverização que proporcionem maior deposição da calda e de maneira uniforme no alvo, para evitar que algumas plantas daninhas não sejam atingidas pelas gotas pulverizadas, bem como a cultura a ser manejada.

Segundo Ferreira et al. (2000), o sucesso da dessecação consiste em uma cobertura mínima, uniforme e de elevada qualidade e está diretamente relacionado com o diâmetro das gotas, que também estabelece o seu comportamento quanto à distância de deslocamento (deriva), à penetração na folhagem, à perda por evaporação e, conseqüentemente, à taxa de recuperação.

Assim, as pontas avaliadas neste trabalho foram eficientes na dessecação das plantas de $B$. brizantha cv. Marandu com o herbicida glyphosate, independentemente do volume de aplicação utilizado. Foi constatada, também, a possibilidade de redução do volume de aplicação na dessecação de pastagens, em aplicações de herbicidas sistêmicos. Contudo, é extremamente importante ressaltar que a utilização de volumes de aplicação reduzidos e de pontas de pulverização que produzem gotas finas na dessecação de plantas de braquiárias deve respeitar as condições climáticas no momento do manejo, a fim de que possam ser evitados problemas de deriva e ambientais.
Dessa forma, devem ser realizados mais estudos nessa área que avaliem doses menores de dessecante, bem como novas pontas de pulverização que permitam a redução do volume de aplicação sem prejudicar a distribuição das gostas no alvo e que minimizem as perdas por deriva.

\section{LITERATURA CITADA}

ALMEIDA, F. S. Controle de plantas daninhas em plantio direto. Londrina: Instituto Agronômico do Paraná, 1991. 34 p. (Circular, 67).

BUHLER, D. D.; BURNSIDE, O. C. Effects of application variables on glyphosate phytotoxicity. Weed Technol., v. 1, n. 1, p. 14-17, 1987.

COSTA, E. A. D. Efeitos de surfactantes sobre a tensão superficial de soluções de rodeo. 1997. 73 f. Dissertação (Mestrado em Agronomia/Proteção de Plantas) -

Universidade Estadual Paulista, Botucatu, 1997.

CORDEIRO, A. M. C. Como a tecnologia de aplicação de produtos fitossanitários pode contribuir para o controle de pragas, doenças e plantas daninhas. In: ZAMBOLIM, L.

Manejo integrado: fitossanidade, cultivo protegido, pivô central e plantio direto. Viçosa-MG: Universidade Federal de Viçosa, 2001. p. 683-721

CRISTOFOLETTI, J. C. Considerações sobre a deriva nas pulverizações agrícolas e seu controle. 1998. 19 p. Apostila. 
CUNHA, J. P. A. R. Tecnologia de aplicação do chlorothalonil no controle de doenças do feijoeiro. 2003 81 f. Tese (Doutorado em Mecanização Agrícola) Universidade Federal de Viçosa, Viçosa, MG, 2003.

FERREIRA, G. A. et al. Comparação de bicos de pulverização na dessecação do milheto (Pennisetum americanum). Pesq. Agropec. Trop., v. 30, n. 1, p. 65-70, 2000 .

FOLONI, L. L. Respostas da utilização de bicos de baixa vazão com glyphosate e sulfosate no controle de arroz vermelho, em aplicação de pré-plantio, em área de plantio direto de arroz (Oryza sativa L.) In: REUNIÃO DA CULTURA DO ARROZ IRRIGADO, 21., Porto Alegre, 1995. Anais... Porto Alegre: 1995. p. 253.

GREGO, C. R.; BENEZ, S. H. Manejo da cobertura vegetal do solo na implantação da cultura da soja (Glycine max (L.) Merril) semeada com dois mecanismos sulcadores. Energia Agric., v. 18, n. 3, p. 48-52, 2002.

JORDAN, T. N. Effects of diluent volumes and surfactant on the phytotoxicity of glyphosate to bermudagrass (Cynodon dactylon). Weed Sci., v. 29, n. 1, p. 79-83, 1981

MACIEL, C. D. G. et al. Avaliação do depósito e distribuição da calda de pulverização em plantas de feijoeiro e Braquiaria decumbens. Planta Daninha, v. 19, n. 1, p. 103-110, 2001

MACIEL, C. D.; VELINI, E.; BERNARDO, R. S. Desempenho de pontas de pulverização em Brachiaria brizantha $\mathrm{cv}$. mg-4 para controle de ninfas de cigarrinhas das pastagens. Eng. Agríc., v. 27, n. 1, p. 66-74, 2007

McWHORTER, C. G.; HANKS, J. E. Effect of spray volume and pressure on postemergence johnsongrass (Sorghum halepense) control. Weed Technol., v. 7, n. 2, p. 304-310, 1993.

NEGRISOLI, E. et al. Depósitos unitários de calda de pulverização com e sem surfactante em plantas de Salvinia molesta. Planta Daninha, v. 20, p. 51-6, 2002. Edição Especial.

PALLADINI, L. A. Metodologia para a avaliação da deposição em pulverizações. 2000. 110 f. Dissertação (Doutorado em Agronomia) - Universidade Estadual Paulista, Botucatu, 2000
RODRIGUES, A. C. P. Efeito de pontas e volumes de aplicação sobre os depósitos da pulverização em plantas de feijoeiro, Bidens pilosa L. e Brachiaria plantaginea (Link) Hitchc. 2006. 76 f. Dissertação (Mestrado em Agronomia) - Universidade Estadual Paulista, Botucatu, 2006.

SOCIEDADE BRASILEIRA DA CIÊNCIA DAS PLANTAS DANINHAS - SBCPD. Procedimentos para instalação, avaliação e análise de experimentos com herbicidas. Londrina: 1995. 42 p.

SOUZA, R. T.; VELINI, E. D.; PALLADINI, L. A. Aspectos metodológicos para análise de depósitos de pulverizações pela determinação dos depósitos pontuais. Planta Daninha, v. 25, n. 1, p. 195-202, 2007.

SPRAYING SYSTEMS Co. Teejet spray products. Guia do compador 201-BR/P. 2000. 29 p.

TAYLOR, W. A.; SHAW, G. B. The effect of drop speed, size and surfactant on the deposition of spray on barley and radish or mustard. Pest. Sci., v. 14, n. 6, p. 659-65, 1993.

TIMOSSI, P. C.; DURIGAN, J. C.; LEITE, G. J

Interferência da dessecação de coberturas vegetais, em plantio direto, sobre a emergência e crescimento inicial de soja. In: CONGRESSO BRASILEIRO DA CIÊNCIA DAS PLANTAS DANINHAS, 24., 2004, São Pedro. Anais... São Pedro: Sociedade Brasileira da Ciência das Plantas Daninhas, 2004. CD-ROM.

TOMAZELA, M. S. Efeito do estágio de desenvolvimento de Brachiaria plantaginea (Link) Hitch, volume e ângulo de aplicação na deposição de calda de aplicação. 2001. 52 f. Tese (Doutorado em Agronomia/ Agricultura) - Universidade Estadual Paulista, Botucatu, 2001.

VELINI, E. D. Estudos e desenvolvimento de métodos experimentais e amostrais adaptados à matologia. 1995. 250 f. Tese (Doutorado em Agronomia/Produção Vegetal) Universidade Estadual Paulista. Jaboticabal, 1995

ZAR, J. H. Biostatistical analysis. 2. ed. Englewood Cliffs: Prentice Hall, 1984. 718 p. 